\title{
ANTICHOLINESTERASE ACTIVITY OF OCTA PEPTIDES RELATED TO HUMAN HISTATIN 8: IN-SILICO DRUG DESIGN AND IN-VITRO
}

\section{PANDURANGAN PERUMAL ${ }^{1 *}$, VASUDEVAN MANI ${ }^{2}$, SRIDEVI CHIGURUPATI ${ }^{1}$, MANIKANDAN SELVARA ${ }^{3}$}

${ }^{1}$ Department of Pharmaceutical Chemistry, Faculty of Pharmacy, Asian Institute of Medicine, Science and Technology University, 08100 Bedong, Kedah Darul Aman, Malaysia. ${ }^{2}$ Department of Pharmaceutical Chemistry, Faculty of Pharmacy, Al Qassim University, Qassim, Al qassim, Saudi Arabia. ${ }^{3}$ Department of Bio-informatics Centre, Integrative Pharmacogenomics Institute, Universiti Teknologi MARA, 42300 Bandar Puncak Alam, Selangor Darul Ehsan, Malaysia. Email: perupharma78@gmail.com

Received: 14 February 2017, Revised and Accepted: 10 March 2017

\section{ABSTRACT}

Objective: To evaluate the octapeptides related to human histatin 8 by in-silico and in-vitro studies.

Method: Schrodinger, LLC and Ellman's method.

Results: The compound HH1 and HH2 was found to be potent docking score of -9.494 and -7.401 against acetylcholinesterase (AChE) enzyme. The $\mathrm{IC}_{50}$ value of $\mathrm{HH} 1$ and $\mathrm{HH} 2$ was found to be $0.39 \pm 0.28$ and $0.78 \pm 0.15 \mu \mathrm{g} / \mathrm{mL}$. However, these compounds are shown to be highly effective as compared with the control AChE inhibitor donepezil $(0.065 \pm 0.0050 \mu \mathrm{g} / \mathrm{mL})$.

Conclusion: In-silico docking study was conducted for the designed octapeptides related to human histatin 8 against AChE enzyme shows significance binding affinity toward $\mathrm{HH} 1$ and $\mathrm{HH} 2$ peptides and the AChE inhibitory activity of octapeptides shown to be a highly potent inhibitor as compared with control donepezil.

Keywords: Alzheimer's disease, Octapeptides, In-silico, In-vitro, Acetyl cholinesterase.

(C) 2017 The Authors. Published by Innovare Academic Sciences Pvt Ltd. This is an open access article under the CC BY license (http://creativecommons. org/licenses/by/4. 0/) DOI: http://dx.doi.org/10.22159/ajpcr.2017.v10i6.17697

\section{INTRODUCTION}

Most of the drugs approved for AD treatment are acetylcholinesterase (AChE) inhibitors, which improve the AChE level in the brain by decreasing the hydrolysis of AChE. $\beta$ amyloid $(A \beta)$ formed by the continuously proteolytic processing of $\beta$-amyloid precursor protein by $\beta$-secretase and $\gamma$-secretase, plays a vital part in the pathogenesis of AD [1]. Recent evidence indicated certain links between $A \beta$ and AChE [2]. Right now the development of single molecule may possess multiple concomitant biological properties and would have more advantages than combination therapy due to deficient of drugs which are monofunctional, defeat only a single target. Furthermore, the risk of drug-drug interactions can be reduced, and the therapeutic treatment has significantly simplified and better patient compliance [3]. Current scenario, peptides are the alternative of heterocyclic compounds in pharmaceutical industry. Short peptides are linear molecules having 2-20 amino acids present in the sequence of the peptide. Right now more than 50 healing peptides are available in the market and some of the peptides are in clinical trials [4] (phase I-III). To overcome the risk factor of peptide delivery, balancing of hydrophobic and hydrophilic characters (amphiphile) [5]. Short and ultra-short peptides were inhibiting aggregation of $A \beta$ and reduce its toxic effects. It is also shown to be effective in AD rodent animal models [6]. Based on the above factors, to evaluate the octapeptides related to human histatin 8 by in-silico and in-vitro method and correlate both. Synthetic part of the octapeptides related to human histatin 8 was published earlier [7].

\section{MATERIALS AND METHODS}

\section{Materials}

Chemicals

Acetylthiocholine iodide (ATCI), sodium phosphate buffer and AChE were purchased from SIGMA-ALDRICH. 5, 5-dithio-bis-(2-nitrobenzoic acid) (DTNB) from Thermo Fisher Scientific. Buffers and other chemicals were of analytical grade.

\section{Instruments}

Ultraviolet-visible spectroscopy spectrophotometer from SHIMADZU and incubator from Thermo Scientific.

\section{Methods}

Molecular docking studies with octapeptides

Initially, the octapeptides ( $\mathrm{HH} 1, \mathrm{HH} 2$, and $\mathrm{HH} 3$ ) sequences de novo peptide structure was predicted using the PEP-FOLD server at mobile server portal [bioserv.rpbs.univ-paris-diderot.fr/services/PEP-FOLD/].

Before docking the X-ray crystal structures of acetyl cholinesterase (AChE) with pdb id: 1EVE were retrieved from the RCSB Protein Data Bank [8-10]. Their corresponding protein structures were subsequently prepared using the Protein Preparation Wizard in the Schrödinger software suite [11]. The respective AChE structure is optimized by removing the water molecules, heteroatoms, and cofactors. Hydrogen, missing atoms, bonds, and charges were computed. Further, all the three octapeptides were docked to $\mathrm{AChE}$ using guide peptide docking procedure [11].

Further, receptor grid was generated around the AChE enzyme active site by choosing centroid of AChE enzyme complexed ligand (aricept), with the grid box size set to $20 \AA$ radius using receptor grid generation panel implemented in Glide [11].

The ligand structures (Fig. 1) were constructed using the splinter dictionary of Maestro 9.3 (Schrodinger, LLC) using the Optimized Potentials for Liquid Simulations-All Atom (OPLS-AA) force field with the steepest descent followed by curtailed Newton conjugate gradient protocol. Partial atomic charges were computed using the OPLS-AA force field.

All the octapeptides (HH1, HH2, and HH3) docking calculations were performed using standard precision peptide docking mode. The Glide 


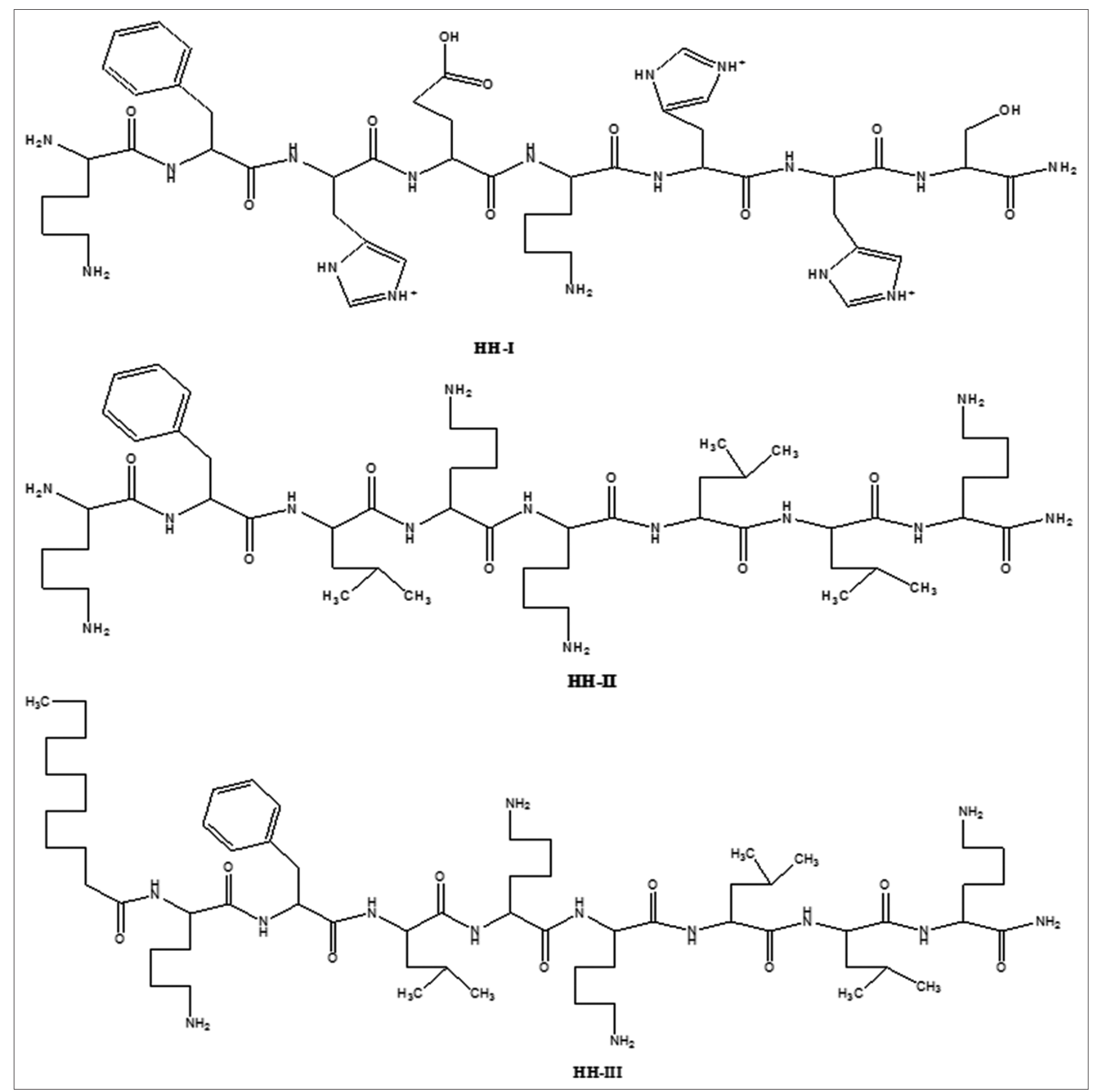

Fig. 1: The ligand structures

docking score was used to determine the best-docked structure from the output. The binding affinity of the AChE/octapeptides complexes was expressed as docking scores. The interactions of these docked complexes were further analyzed using PyMOL [12].

\section{Anti-alzheimer's activity}

\section{In-vitro AchE assay}

The assay for measuring AChE activity was evaluated based on Ellman's method [13,14]. The principle of this method is based on enzyme hydrolyzes the substrate ATCI into thiocholine and acetic acid. Then, thiocholine is allowed to react with DTNB, and formation of yellow color. The intensity of color formation proportional to the activity of the enzyme.

Briefly, $150 \mu \mathrm{l}$ of $0.1 \mathrm{M}$ sodium phosphate buffer (pH 8.0), $10 \mu \mathrm{l}$ of the test compound, and $20 \mu \mathrm{l}$ of the enzyme solution $(0.1 \mathrm{units} / \mathrm{mL})$ were added and incubated for 15 minutes at $25^{\circ} \mathrm{C}$. After that followed by mixed with $10 \mu \mathrm{l}$ of DTNB $(10 \mathrm{mM})$ and $10 \mu \mathrm{l}$ of ATCI $(14 \mathrm{mM})$ to initiate the reaction, incubate for 10 minutes. The color formation was measured at $410 \mathrm{~nm}$ wavelength. The controls contained the solvent to dissolve the compound instead of test compound. The percentage inhibition for each test solution was then calculated using the following equation:

Inhibition $(\%)=(1-$ absorbance sample $/$ absorbance control $) \times 100$

\section{RESULTS AND DISCUSSION}

\section{Docking with octapeptides on AchE}

From docking analysis of all the three octapeptides, it was found that HH1 and HH2 dock to AChE with docking score of -9.494 and -7.401 with the corresponding $\mathrm{IC}_{50}: 0.39 \pm 0.28$ and $\mathrm{IC}_{50}: 0.78 \pm 0.15 \mu \mathrm{g} / \mathrm{mL}$, while HH3 peptide did not dock as the peptide was not stable to bind 
to the AChE active site. This result is also in accordance with $\mathrm{HH} 3$ $\mathrm{IC}_{50} 86.45 \pm 0.32$ value, showing declined anticholinesterase enzyme inhibition activity. The binding mode of the HH1 peptide to AChE structure shows that the amino terminal end residue Lys1 backbone $\mathrm{NH}$ form a hydrogen bond with side chain oxygen of Asn280. While the phe 2 of HH1 forms a hydrophobic interaction with side chain of Tyr70. Following it HH1 peptide residue His3 side chain imidazole ring nitrogen forms a hydrogen bond with $\mathrm{Gln} 74$ side chain $\mathrm{NH}$, while Glu4 of peptide did not show any key interaction. In the case of Lys6, its side chain aliphatic alkane part forms a hydrophobic interaction with Phe290, Phe331, and Tyr334. Interestingly, face-to-face $\pi-\pi$ stacking between Phe330 and with imidazole ring of His6, while the His7 imidazole $\mathrm{NH}$ forms a hydrogen bond with Tyr70 backbone oxygen. In addition, the peptide Ser8 backbone forms a hydrogen bond with Tyr130 side chain $\mathrm{OH}$ and finally the terminal $\mathrm{OH}$ forms a hydrogen bond with one of the side chain oxygen of Glu199 (Fig. 2a).

The binding mode of the $\mathrm{HH} 2$ peptide (gray stick) in the AChE active site, where the $\mathrm{HH} 2$ peptide residues Lys 1 and Lys4 side chain's one of the $\mathrm{NH}$ of $\mathrm{NH}^{+}$forms a hydrogen bond with Glu73 backbone oxygen and side chain oxygen of Asn280, respectively. While the Leu6 backbone $\mathrm{NH}$ forms a hydrogen bond with side chain $\mathrm{OH}$ of Tyr70. Meanwhile, the backbone oxygen and $\mathrm{NH}$ of Leu7 forms hydrogen bonds with Tyr121 side chain $\mathrm{OH}$. Finally, the carboxyl terminal residue Lys8's side chain forms a hydrogen bond with backbone oxygen is 440 (Fig. 2b).

\section{In-vitro AchE assay}

The assay of AChE was based on an improved Ellman's method in a 96 well plate reader using QuantiChrome assay kit (USA). One of the characteristic changes that occur in $\mathrm{AD}$ is an increase in AChE activity, the enzyme responsible for acetylcholine hydrolysis, from

Table 1: $\mathrm{IC}_{50}$ value of octapeptides related to human histatin 8 and control

\begin{tabular}{lll}
\hline S. No & Compounds code & IC $_{\mathbf{5 0}}(\boldsymbol{\mu g} / \mathbf{m L})$ \\
\cline { 2 - 2 } & Concentration of compounds $(\boldsymbol{\mu g} / \mathbf{m L})$ & \\
\hline 1 & HH1 & $0.39 \pm 0.28$ \\
2 & HH2 & $0.78 \pm 0.15$ \\
3 & HH3 & $86.45 \pm 0.32$ \\
\hline
\end{tabular}

Results were expressed as mean $\pm \mathrm{SD}(\mathrm{n}=3)$, IC for donepezil control for $\mathrm{AChE}$ inhibition assay was $0.065 \pm 0.0050 \mu \mathrm{g} / \mathrm{mL}$, AChE: Acetylcholinesterase

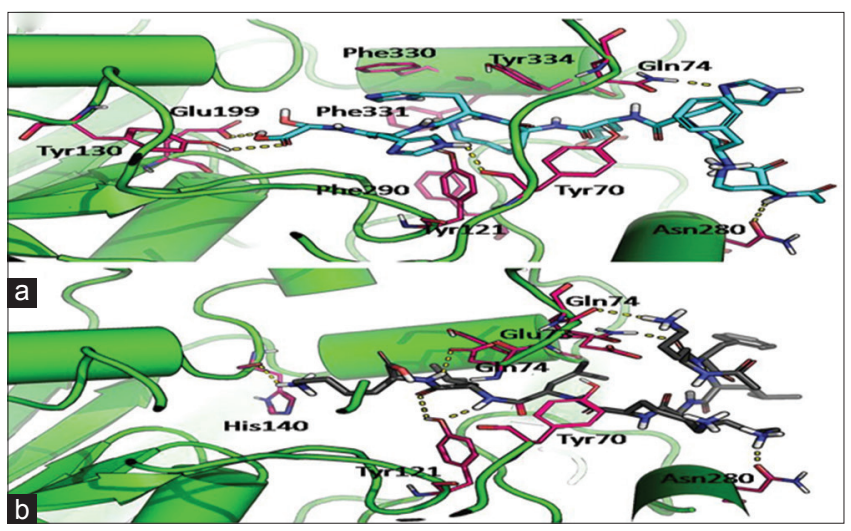

Fig. 2: Shows the binding mode (a) HH1 peptide (blue stick), (b) $\mathrm{HH} 2$ peptide (gray stick), in the acetyl cholinesterase active site. The key interacting residues are shown in magenta color lines, and the hydrogen bonds are represented as yellow dashed lines both cholinergic and non-cholinergic neurons of the brain. The results obtained from the octapeptides related to human histatin 8 against AChE enzyme inhibition activity and the percentage inhibition was evaluated and tabulated in Table 1. $\mathrm{IC}_{50}$ value of $\mathrm{HH} 1$ and $\mathrm{HH} 2$ was found to be $0.39 \pm 0.28$ and $0.78 \pm 0.15 \mu \mathrm{g} / \mathrm{mL}$. However, these compounds are shown to be highly effective as compared with the control AChE inhibitor donepezil $(0.065 \pm 0.0050 \mu \mathrm{g} / \mathrm{mL})$.

\section{Statistical analysis}

Data were presented as mean \pm standard deviation. All analyses were performed in triplicates. GraphPad Prism 5 and Microsoft Excel 2007 were used for the statistical and graphical evaluations.

\section{CONCLUSION}

In-silico docking study was conducted for the designed octapeptides related to human histatin 8 against AChE enzyme shows significance binding affinity toward $\mathrm{HH} 1$ and $\mathrm{HH} 2$ peptides. The AChE inhibitory activity of octapeptides related to human histatin 8 was evaluated using Ellman's method, and these compounds are shown to be a highly potent inhibitor as compared with control AChE inhibitor donepezil. In-silico results correlates with the in-vitro results. The result showed that $\mathrm{HH} 1$ and $\mathrm{HH} 2$ exhibited more capability to inhibit AChE enzyme.

\section{REFERENCES}

1. John V, Beck JP, Bienkowski MJ, Sinha S, Heinrikson RL. Human beta-secretase (BACE) and BACE inhibitors. J Med Chem 2003:46:4625-30

2. Pákáski M, Kálmán J. Interactions between the amyloid and cholinergic mechanisms in Alzheimer's disease. Neurochem Int 2008;53(5):103-11.

3. Small G, Dubois B. A review of compliance to treatment in Alzheimer's disease: Potential benefits of a transdermal patch. Curr Med Res Opin 2007;23(11):2705-13.

4. Perumal P, Pandey VP. Antimicrobial peptides: The role of hydrophobicity in the alpha helical structure. J Pharm Pharmacogn Res 2013;1(2):39-53.

5. Hollmann A, Martínez M, Noguera ME, Augusto MT, Disalvo A, Santos NC, et al. Role of amphipathicity and hydrophobicity in the balance between hemolysis and peptide-membrane interactions of three related antimicrobial peptides. Colloids Surf B Biointerfaces 2016;141:528-36.

6. Funke SA, Willbold D. Peptides for therapy and diagnosis of Alzheimer's disease. Curr Pharm Des 2012;18(6):755-67.

7. Perumal P, Pandey VP, Prabhu S. Antimicrobial activity of octapeptides related to human histatin 8. Eur J Pharm Med Res 2015;2(1):526-52.

8. Kryger G, Silman I, Sussman JL. Structure of acetylcholinesterase complexed with E2020 (Aricept): Implications for the design of new anti-Alzheimer drugs. Structure 1999;7(3):297-307.

9. Perumal P, Pandey VP. Docking studies on antimicrobial peptides related to apidaecin-IA and human histatin against glutamine synthetase and RNA polymerase in Mycobacterium tuberculosis. Asian J Pharm Clin Res 2014;7(5):195-201.

10. Krishnapriya MV, Sumathi T, Chinnasamy A, Balakrishnan G, Renjith P. Comparative analysis of potentiality of esculin and hinokitol ( $\beta$-thujaplicin) as anti-parkinsonism drugs: A pilot in silico study. Int J Pharm Pharm Sci 2016;9(1):108-15.

11. Maestro. Schrodinger Release. Version 10.1. New York: Schrodinger, LLC; 2015.

12. Schrödinger, LLC. PyMOL Molecular Graphics System. New York, USA: Schrodinger, LCC; 2010.

13. Ellman GL, Courtney KD, Andres V Jr, Feather-Stone RM. A new and rapid colorimetric determination of acetylcholinesterase activity. Biochem Pharmacol 1961;7(2):88-95.

14. Sachin SS, Archana RJ, Manoj NG. In-vitro antioxidant and antiinflammatory activity of methanol extract of Oxalis corniculata Linn. Int J Pharm Pharm Sci 2010;2(1):146-55. 